\title{
La salud mental ante los desastres naturales
}

\author{
Valerio Villamil Salcedo'
}

Editorial

La aparición del presente número de la revista SALUD MENTAL coincide con el Día Internacional para la Reducción de los Desastres Naturales. Los desastres naturales y los provocados por el hombre han existido desde siempre, sin embargo, en los últimos años se les ha prestado mayor atención debido a los problemas subyacentes que traen consigo, especialmente sobre la salud mental. Es por eso que el 8 de octubre de 2008 se declaró como el Día Internacional para la Reducción de los Desastres Naturales; ${ }^{1}$ el motivo de dicha declaración se debió al terremoto de Cachemira (también conocido como Terremoto del subcontinente Indio, Terremoto del norte de Pakistán y Terremoto del sur de Asia) el cual tuvo lugar el 8 de octubre de 2005 en la región de Cachemira, entre la India y Pakistán. Este terremoto ocasionó la muerte de 73000 personas en $\mathrm{Pa}$ kistán, 106000 heridos, tres millones de personas sin hogar, y dejó sin ropa para el invierno a miles de niños y niñas que en aquel momento vivían en tiendas de campaña o en refugios de cartón y piedra. ${ }^{2,3}$ Por tal motivo los Estados miembros de las Naciones Unidas se comprometieron a tomar medidas para reducir el riesgo de desastres y a adoptar un lineamiento denominado Marco de Acción de Hyogo o Marco de Hyogo $(\mathrm{MAH})$ para reducir las vulnerabilidades frente a las amenazas naturales. El objetivo de este instrumento es aumentar la resiliencia de las naciones y las comunidades ante los desastres para el año 2015, logrando una reducción considerable de las pérdidas que ocasionan los desastres, tanto de vidas humanas como en los bienes sociales, económicos y ambientales de las comunidades y los países. ${ }^{4}$

Paradójicamente, y por una coincidencia del destino, en 1992 (13 años antes), la Federación Mundial para la Salud Mental y la Organización Mundial de la Salud propusieron el 10 de octubre como el día de la Salud Mental, el cual se celebra cada año para concentrar la atención mundial en la identificación, tratamiento y prevención de algún trastorno emocional o de la conducta. El objetivo de celebrar este día fue sensibilizar al público acerca de este tipo de enfermedades y fomentar el debate franco sobre los trastornos mentales y las inversiones en servicios de prevención, promoción y tratamiento. ${ }^{5}$
Por tal motivo, la atención de la salud mental en situaciones de desastres es una necesidad cada vez más importante debido a la angustia, desesperanza, impotencia, enojo, tristeza y ansiedad que traen consigo, hasta eventos más graves como el abuso de sustancias (principalmente alcohol), depresión, trastorno por estrés post-traumático y otros. ${ }^{6}$

Los desastres naturales y los provocados por el hombre llamaron la atención de los organismos internacionales sobre la afectación de la salud mental de las personas que están expuestas a eventos catastróficos. Es así que la Organización Mundial de la Salud y la Organización Panamericana de la Salud colocaron a disposición, en su página de Internet, una serie de artículos, libros y noticias que ofrecen información que ayuda a los equipos de salud para la toma de decisiones y poder enfrentar este problema. Sin embargo, aún conocemos poco del tema; la información es anecdótica, escasa y poco científica, por lo que es necesario profundizar en el tema y generar equipos de salud mental que se dediquen exclusivamente a la atención de dichos problemas en situaciones de desastre. Es así que la Asociación Mundial de Psiquiatría y la Organización Mundial de la Salud se pronunciaron sobre el papel que debe de desempeñar el psiquiatra en la atención de la salud mental en los desastres, señalando que su labor debe de ser activa y continua. ${ }^{7}$

Finalmente, se sugiere la formación de un equipo de salud mental internacional que brinde apoyo a todas las regiones del mundo. Para generar dicho equipo es necesario capacitar a un personal multidisciplinario (psiquiatras, internistas, médicos familiares y generales, enfermeras, trabajadoras sociales, psicólogos, entre otros), contar con una cédula profesional internacional que permita prescribir psicofármacos en cualquier parte del mundo y tener acceso a los medicamentos básicos. Indudablemente, el apoyo psicoterapéutico es imprescindible, ya que las consecuencias y daño a la salud mental se observan a mediano y largo plazo por lo que la formación de orientadores en salud mental (líderes comunitarios, maestros de escuela y padres de familia) se hace una necesidad cada vez más importante. 


\section{REFERENCIAS}

1. Naciones Unidas. Mensaje del Secretario General con ocasión del Día Internacional para la Reducción de los Desastres Naturales. 2008. http://www.un.org/es/sg/messages/2008/disasterday2008.html (último ingreso 4 de julio de 2014).

2. Naciones Unidas. E/ICEF/2008/P/L.11. Consejo Económico y Social. Fondo de las Naciones Unidas para la Infancia. Junta Ejecutiva. Período de sesiones anual de 2008. República Islámica del Pakistán. http:// daccess-dds-ny.un.org/doc/UNDOC/LTD/N08/305/12/PDF/N0830512. pdf?OpenElement (último ingreso 7 de julio de 2014).

3. Naciones Unidas. A/RES/60/13. Resolución aprobada por la Asamblea General el 14 de noviembre de 2005. 60/13. Fortalecimiento de las actividades de socorro de emergencia, rehabilitación, reconstrucción y prevención tras el desastre provocado por el terremoto del Asia meridional-Pakistán. http://daccess-dds-ny.un.org/doc/UNDOC/GEN/ N05/488/35/PDF/N0548835.pdf?OpenElement (último ingreso 7 de julio de 2014).
4. Estrategia Internacional para la Reducción de Desastres (EIRD). Marco de Acción de Hyogo 2005-2015: Aumento de la resiliencia de las naciones y las comunidades ante los desastres. Ginebra, Suiza. 2005. http://www.preventionweb.net/files/1217_HFAbrochureSpanish.pdf (último ingreso 4 de julio de 2014).

5. http://www.euskonews.com/0411zbk/gaia41102es.html (último ingreso 4 de julio de 2014).

6. Villamil Salcedo V, López Rodríguez J, Cortina De la Fuente D, González Olvera J. Salud mental en casos de desastre. Revista de Psiquiatría. 2007;23(2):21-23.

7. Uriarte JJ. Declaración de la Asociación Mundial de Psiquiatría (WPA) y la Organización Mundial de la Salud (OMS) sobre el papel de los psiquiatras en las situaciones de desastres1 (2006). En: Cuadernos de Psiquiatría Comunitaria. Rehabilitación Psicosocial. Asociación Asturiana de Neuropsiquiatría y Salud Mental. Oviedo, España. Vol. 7, N. ${ }^{\circ}$ 2, pp. 163-164, 2007. http://doentacion.aen.es/web/docs/ Cuadernos7.2.pdf\#page=86 (último ingreso 7 de julio de 2014). 